\title{
Design of Efficycle - Human Powered Hybrid Tricycle with inbuilt Programmable Position Control Gear Shifter using Stepper Motor
}

\author{
Upendra S. Gupta ${ }^{\# 1}$,Sumit Chandak ${ }^{* 2}$, Devashish Dixit ${ }^{\# 3}$ \\ ${ }^{1,2}$ Reader SVITS Indore
}

Abstract- This paper provides in-detail description of the design considerations, analysis and mathematical data involved in the design of a hybrid tri-cycle. The tri-cycle is powered by two humans simultaneously and also by a 373 Watt Geared PMDC. It is an eco friendly human powered vehicle with a compounded electric drive system. The focus has been laid on the simplicity of design, high performance, easy maintenance and safety at very reasonable prices .Most of the components have been chosen keeping in mind the easy availability and reliability. According to recognition of customer's need we are going to design a vehicle which is ergonomic, aerodynamic, highly engineered and easily manufactured. The tadpole type of trike has two wheels in the front and one wheel in the rear. A Tadpole trike's front-end exhibits less acceleration than the rear end when turning. This allows the trike to negotiate corners at great speed and stability. The concept used in the innovation is programmable position control of gear shifter using stepper motors. Position of motors is controlled with respect to speed by programming which in turn controls the position of gear shifter. This technology is used in robotics \& position controlling of robotic arms. It has got a wide scope in automotive industry as it reduces the efforts of driver $\&$ provides more automatic control of the vehicle. Hence it makes the vehicle more efficient. Human powered hybrid vehicle present the new milestone in the realm of "Green Technology".

Keywords - Efficycle, pollution, hybrid, mechanical, green Technology

\section{INTRODUCTION}

With conventional fossil fuel consuming rides posing a threat to the existence of life on earth, it is high time to develop alternate and greener modes of transportation for a sustainable future. The Effi-cycle was designed to be an electrically assisted, dual-human powered tricycle. Different topologies were analyzed and based on the factors such as turning radius, stability, handling and ease of manoeuvring, tadpole design was adopted with 2 wheels at the front and one at the back. The vehicle has an innovative tadpole design which is ergonomic, highly engineered and easy to manufacture. The design has been laid on the simplicity in design, high performance, easy maintenance and safety at very reasonable prices. The design was then simulated on system with the help of software namely solid works. The analysis was done on Ansys software for the tests like Front Impact, Side Impact, Rear Impact \& Rollover Impact tests.

\section{Design Methodologies}

\section{A. Frame Configuration, Design \& Material}

A tadpole trike's front-end exhibits less acceleration than the rear end when turning. This allows the trike to negotiate corners at great speed and stability. Two wheels in front offer excellent overall braking and overall excellent handling. The FEM analysis of the complete frame was carried out with help of analysis software (ANSYS 14.0). Material selection is a step in the process of designing any physical object. We have chosen steel "ST 52.3" over AISI 1018 because it is too light in weight, highly ductile and having high strength. It can be easily welded and having ability to harden in commercial applications.

\begin{tabular}{|l|l|l|l|l|}
\hline Material & $\begin{array}{l}\text { Yield } \\
\text { strength }\end{array}$ & $\begin{array}{l}\text { Outer } \\
\text { diameter }\end{array}$ & Thickness & $\begin{array}{l}\text { carbon } \\
\text { percentage }\end{array}$ \\
\hline ST 52.3 & $\begin{array}{l}450 \\
\mathrm{MPa}\end{array}$ & $1.25 \%$ & $1.63 \mathrm{~mm}$ & $0.21 \%$ \\
\hline
\end{tabular}

Table I: Material Properties of ST52.3

\section{B. Frame Configuration, Design \& Material}

The quality of the steering system and geometry also dictates the performance of the trike. The vehicle is provided with fulcrum link mechanism. This system gives the turning radius of $2.72 \mathrm{~m}$.

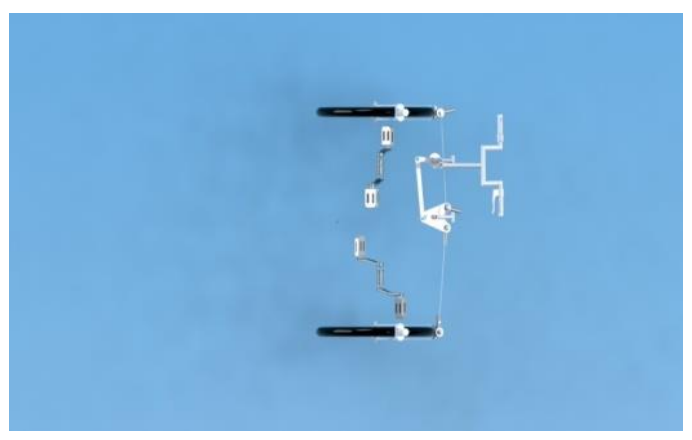

Fig1: Steering System of Trike

\begin{tabular}{|l|l|}
\hline \multicolumn{2}{|c|}{ Steering System } \\
\hline $\begin{array}{l}\text { Steering } \\
\text { mechanism }\end{array}$ & $\begin{array}{l}\text { Fulcrum Link } \\
\text { mechanism }\end{array}$ \\
\hline Control & T-bar \\
\hline Turning radius & $2.72 \mathrm{~m}$ \\
\hline Fork length & $160 \mathrm{~mm}$ \\
\hline Caster head Angle & $19^{\circ}$ \\
\hline Steer angle & $22.44^{\circ}$ \\
\hline Steer ratio & $1: 1$ \\
\hline
\end{tabular}

Table II: Specification of Steering Geometry 


\section{Drive Train}

The vehicle is powered by both human and electric power. The drivers can power the vehicle using the two crank wheels in the front portion of the chassis. These two crank wheels deliver the power to the idler axle mounted in the rear part which ultimately drives the rear wheel through freewheels. The overall manual transmission has a 18 Speed Gear assembly.

Velocity ratio: $\mathrm{i}=\mathrm{n}_{1} / \mathrm{n}_{2}=\mathrm{z}_{1} / \mathrm{z}_{2}$

Length of chain: $n^{*} p \quad(n=$ no: of links)

$\mathrm{n}=2(\mathrm{a} / \mathrm{p})+\left(\mathrm{T}_{2}{ }^{\prime}+\mathrm{T}_{3}\right) / 2+\left[\left(\mathrm{T}_{3}-\mathrm{T}_{2}{ }^{\prime}\right) / 2 \pi\right]^{2} *(\mathrm{p} / \mathrm{a})$

$\mathrm{a}=$ Distance of centre between axis of driving \& driven shaft

$\mathrm{T}_{2}$ '- Smaller sprocket teeth's

$\mathrm{T}_{3}$ - Larger sprocket

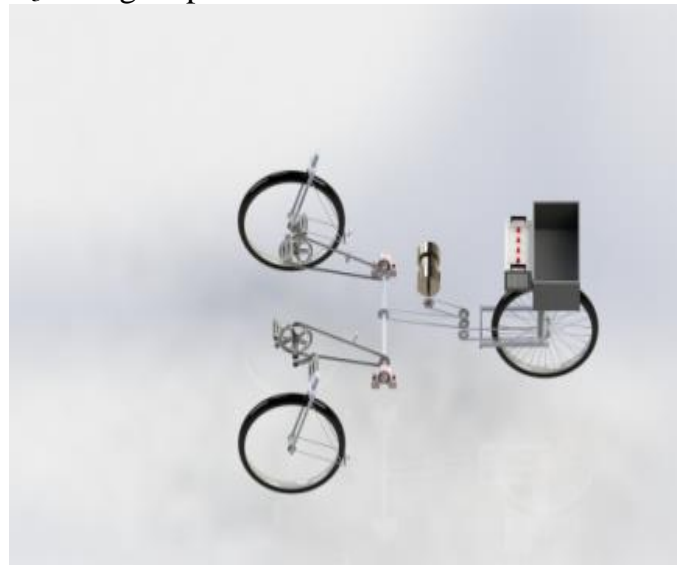

Fig2: Drive Train Powered by Human Drive

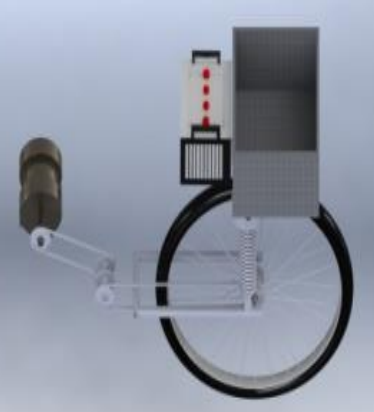

Fig3 :Drive Train Powered by Electrical Drive

\begin{tabular}{|l|l|l|l|l|l|}
\hline S.No. & $\mathrm{T}_{2}{ }^{\prime}$ & $\mathrm{T}_{3}$ & $\mathrm{~V} . \mathrm{R}=\left(\mathrm{T}_{2}{ }^{\prime} / \mathrm{T}_{3}\right)$ & $\mathrm{N}_{3}=\mathrm{V} . \mathrm{R} * \mathrm{~N}_{2}$ & $\begin{array}{l}\text { SPEED } \\
(\mathrm{Km} / \mathrm{hr})\end{array}$ \\
\hline 1. & 24 & 28 & 0.857 & 77.13 & 9.595 \\
\hline 2. & 24 & 26 & 0.923 & 83.07 & 10.334 \\
\hline 3. & 24 & 21 & 1.142 & 102.78 & 12.786 \\
\hline 4. & 24 & 18 & 1.333 & 119.97 & 14.924 \\
\hline 5. & 24 & 16 & 1.500 & 135.00 & 16.794 \\
\hline 6. & 24 & 14 & 1.714 & 154.26 & 19.190 \\
\hline 7. & 34 & 28 & 1.214 & 109.26 & 13.591 \\
\hline
\end{tabular}

Calculations of suspension: For rear suspension system:

Length of spring $=$ solid length $+\max$

Compression + clearance

$=(\mathrm{n}+3) \mathrm{d}+\delta \max +0.15 \delta \max$

$=(14+3) 10+100+0.15 * 100$

$=285 \mathrm{~mm}$

Pitch of coil $=(\mathrm{Lf}-\mathrm{Ls}) / \mathrm{n}+\mathrm{d}$

Table 5: Specification of Suspension System

$=(285-170) / 16+10=17.18$ 


\begin{tabular}{|l|l|}
\hline Natural frequency & $3 \mathrm{~Hz}$ \\
\hline Spring stiffness & $8658 \mathrm{~N} / \mathrm{m}$ \\
\hline Spring index & 5 \\
\hline Mean coil diameter & $50 \mathrm{~mm}$ \\
\hline
\end{tabular}

Table V: Specification of Suspension System

\section{E. Brakes}

We are using mechanical disc brakes, which are mounted on all three wheels. Disc brakes are used because of its High heat dissipation capability, high torque transmitting capacity; good efficiently in wet weather conditions (because centrifugal force tends to fling water off the brake disc and keeps it dry). It does not have Self locking capability. As alternative, Hydraulic drum brake could be used but the vehicle is not a high power vehicle also it is not good in wet weather. Non hydraulic shoe brakes are not used because the shoe gets rubbed so it is not so efficient.

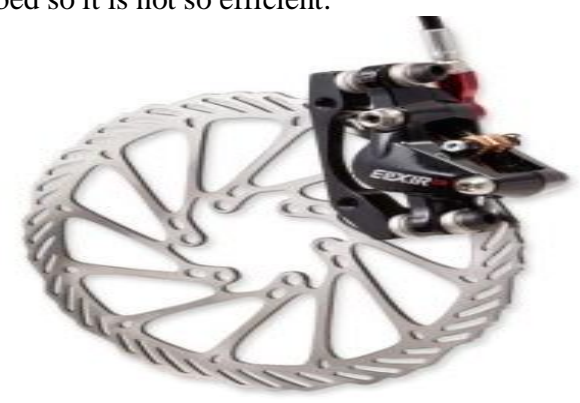

Fig4: Disc Brake System

\begin{tabular}{|l|l|l|l|}
\hline $\begin{array}{l}\text { Max } \\
\text { velocity of } \\
\text { vehicle }\end{array}$ & $\begin{array}{l}35 \\
\mathrm{~km} / \mathrm{hr}\end{array}$ & $\begin{array}{l}\text { Internal } \\
\text { diameter of } \\
\text { disc }\end{array}$ & $120 \mathrm{~mm}$ \\
\hline $\begin{array}{l}\text { Coefficient } \\
\text { of friction }\end{array}$ & 0.4 & $\begin{array}{l}\text { External } \\
\text { diameter of } \\
\text { disc }\end{array}$ & $140 \mathrm{~mm}$ \\
\hline $\begin{array}{l}\text { Braking } \\
\text { efficiency }\end{array}$ & $50 \%$ & Thickness & $3 \mathrm{~mm}$ \\
\hline $\begin{array}{l}\text { Stopping } \\
\text { distance }\end{array}$ & $4.8 \mathrm{~m}$ & $\begin{array}{l}\text { Brake } \\
\text { torque }\end{array}$ & $135 \mathrm{~N}-\mathrm{m}$ \\
\hline $\begin{array}{l}\text { Stopping } \\
\text { time }\end{array}$ & $\begin{array}{l}3.36 \\
\mathrm{sec}\end{array}$ & $\begin{array}{l}\text { Braking } \\
\text { force }\end{array}$ & $409.99 \mathrm{~N}$ \\
\hline
\end{tabular}

Table VI: Specification of Disc Braking System

\section{F. Wheels \& Tyres}

Tires provide contact between the road and the vehicle. Road shocks are first absorbed by tires and then transmitted to suspension. The tyres are chosen in such a way that it must provide traction in all kind if surfaces without slipping. Wheels which is responsible for the steering responsiveness and effortless steering, targeted top speed can be achieved without any compromise in the COG of the trike. So the size of both the wheels are 26" which also fulfil the need of necessary ground clearance. 26-inch wheels offer excellent rolling resistance and made the ride significantly smoother.

\section{G. Seating arrangement, design and feature:}

In the vehicle side by side seating arrangement is provided because it is comfortable, reduces wheelbase and it provides stability to the vehicle. Fiber seats covered by foam will be clamped by nut bolts

\section{H. Safety provisions for the safety of vehicle, its occupants}

Three point harness, helmets, and elbow and knee guards, safety glasses for eye protection for rider's safety.

a) The placement of key controls in reach of both the drivers easily.

b) Common person, physically handicapped or old age person of the community dependent on others for their mobility can also use these vehicles.

c) Vehicle is free from any kind of sharp edges that can harm rider or crew members.

d) Indicators ensure safety of both riders and bystanders and pedestrians

\section{Otherfeatures}

a) Digital speedometer

b) Automatic gear shifter

\section{J. Ergonomic Features}

a) More stable at medium and high speeds because of the low center of gravity.

b) Two wheels in front offer excellent overall braking.

c) Three point harness, helmets, and elbow and knee guards, safety glasses for eye protection for rider's safety.

d) Do not pull the rider over the handle bars in severe stops

\section{K. Programmable Position Control of gear shifter using Stepper motors}

The concept used in the innovation is programmable position control of gear shifter using stepper motors. Position of motors is controlled w.r.t. speed by programming which in turn controls the position of gear shifter. This technology is used in robotics \& position controlling of robotic arms. It has got a wide scope in automotive industry as it reduces the efforts of driver \& provides more automatic control of the vehicle. Hence it makes the vehicle more efficient.

\begin{tabular}{|l|l|l|l|}
\hline $\begin{array}{l}\text { Gear } \\
\text { No. }\end{array}$ & Speed & $\begin{array}{l}\text { Motor 1 } \\
\text { position(3Speed } \\
\text { in degrees ) }\end{array}$ & $\begin{array}{l}\text { Motor 2 } \\
\text { positon(6Speed) } \\
\text { In degrees }\end{array}$ \\
\hline 1 & 9.595 & 0 & 0 \\
\hline 2 & 10.334 & 0 & 10 \\
\hline 3 & 12.786 & 0 & 20 \\
\hline 4 & 13.591 & 10 & 0 \\
\hline 5 & 14.633 & 10 & 10 \\
\hline 6 & 14.924 & 0 & 30 \\
\hline 7 & 16.794 & 0 & 40 \\
\hline 8 & 16.794 & 20 & 0 \\
\hline 9 & 18.081 & 20 & 10 \\
\hline 10 & 18.126 & 10 & 20 \\
\hline 11 & 19.19 & 0 & 50 \\
\hline
\end{tabular}




\begin{tabular}{|l|l|l|l|}
\hline 12 & 21.13 & 10 & 30 \\
\hline 13 & 23.392 & 20 & 20 \\
\hline 14 & 23.792 & 10 & 40 \\
\hline 15 & 26.121 & 20 & 30 \\
\hline 16 & 27.185 & 10 & 50 \\
\hline 17 & 29.391 & 20 & 40 \\
\hline 18 & 33.589 & 20 & 50 \\
\hline
\end{tabular}

Table VII: Specification of Programmable Position Control Gear Shifter

L. Technical specification of human powered hybrid tricycle

\begin{tabular}{|c|c|c|c|}
\hline $\begin{array}{l}\text { Vehicle } \\
\text { make model }\end{array}$ & Values & $\begin{array}{l}\text { Vehicle make } \\
\text { model }\end{array}$ & Values \\
\hline Wheel base & $65^{\prime \prime}$ & Innovation & $\begin{array}{l}\text { Automatic } \\
\text { Gear Shifter }\end{array}$ \\
\hline Wheel track & $43 "$ & & \\
\hline $\begin{array}{l}\text { Vehicle } \\
\text { make model }\end{array}$ & Values & $\begin{array}{l}\text { Vehicle make } \\
\text { model }\end{array}$ & Values \\
\hline $\begin{array}{l}\text { Overall } \\
\text { length }\end{array}$ & $94.16 "$ & $\begin{array}{l}\text { Turning } \\
\text { radius }\end{array}$ & $2.72 \mathrm{~m}$ \\
\hline $\begin{array}{l}\text { Overall } \\
\text { width }\end{array}$ & $46 "$ & Battery & Lead acid \\
\hline $\begin{array}{l}\text { Overall } \\
\text { height }\end{array}$ & $41.81 "$ & Tyre size & $26^{\prime \prime}$ \\
\hline Roll cage & $\begin{array}{l}\text { Tubular } \\
\text { frame } \\
\text { structure }\end{array}$ & Brake & Disk Brake \\
\hline $\begin{array}{l}\text { Roll cage } \\
\text { weight }\end{array}$ & $18 \mathrm{~kg}$ & $\begin{array}{l}\text { Front } \\
\text { suspension }\end{array}$ & Fork \\
\hline C.G. height & $25.33 "$ & $\begin{array}{l}\text { Overall } \\
\text { weight }\end{array}$ & $200 \mathrm{~kg}$ \\
\hline Max. speed & $35 \mathrm{kmph}$ & $\begin{array}{l}\text { Ground } \\
\text { clearance }\end{array}$ & $8.054 "$ \\
\hline Material & $\begin{array}{l}\text { ST } 52.3 \\
\text { with } \\
1.25 " \\
\text { OD and } \\
1.63 \mathrm{~mm} \\
\text { thickness }\end{array}$ & $\begin{array}{l}\text { Rear } \\
\text { Suspension }\end{array}$ & $\begin{array}{l}\text { Progressively } \\
\text { wound coil } \\
\text { spring } \\
\text { suspension }\end{array}$ \\
\hline
\end{tabular}

Table VIII: Technical Specification of human powered hybrid tricycle

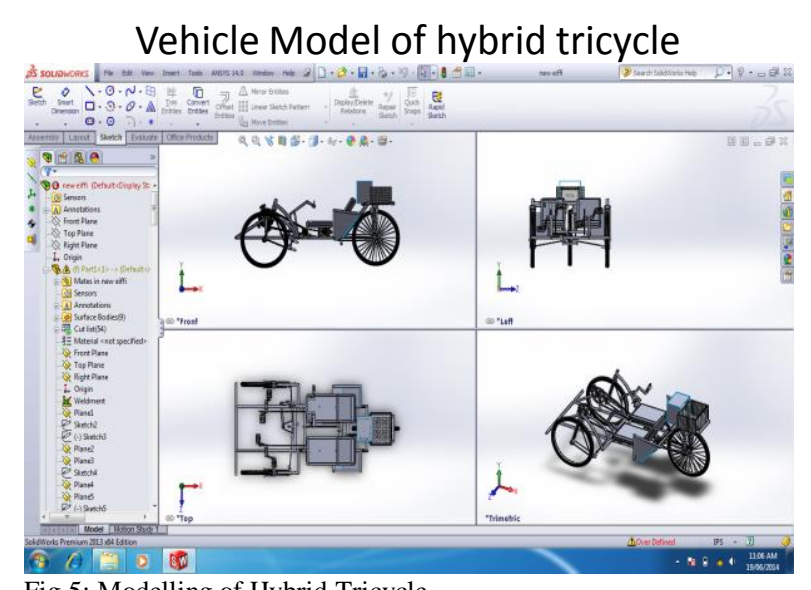

Fig 5: Modelling of Hybrid Tricycle

\section{Results \& Discussion of StRuCture AnAlysis}

An impact test was done using ANSYS12.0 software to check if the chassis could withstand the weight of the drivers and the components associated with the vehicle during static as well as dynamic conditions. The weights were applied at respective seating positions. Similarly, load was applied at specific locations allotted for battery case, electrical components etc. Results obtained proved the chassis to be strong enough for the purpose. A safety factor of 1.4 was obtained, maximum deformation was obtained on roll over $13.56 \mathrm{~mm}$ \& Maximum equivalent Stress was obtained on rollover $433.33 \mathrm{MPa}$

\begin{tabular}{|c|c|c|c|}
\hline $\begin{array}{c}\text { Technical } \\
\text { Parameter }\end{array}$ & Front & Rear & Side \\
\hline $\begin{array}{c}\text { Velocity } \\
(\mathrm{Km} / \mathrm{h})\end{array}$ & 35 & 35 & 30 \\
\hline $\begin{array}{c}\text { Velocity } \\
(\mathrm{m} / \mathrm{s})\end{array}$ & 9.7222 & 9.7222 & 8.3333 \\
\hline Time $(\mathrm{s})$ & 3 & 3 & 3 \\
\hline Force $(\mathrm{N})$ & 6481.481 & 6481.481 & 5555.55 \\
\hline
\end{tabular}

\begin{tabular}{|l|l|l|l|}
\hline $\begin{array}{l}\text { Impact } \\
\text { Mode }\end{array}$ & $\begin{array}{l}\text { Max. } \\
\text { Equivalent } \\
\text { Stress (MPa) }\end{array}$ & $\begin{array}{l}\text { Deformation } \\
(\mathrm{mm})\end{array}$ & F.O.S. \\
\hline Front & 321.22 & 1.79 & 1.4009 \\
\hline Side & 427.8 & 5.23 & 1.0518 \\
\hline Rear & 384.49 & 12.08 & 1.17 \\
\hline Roll over & 433.33 & 13.56 & 1.0384 \\
\hline
\end{tabular}

Table IX: Impact Assessment Data by using Ansys Software12 


\section{FINITE ELEMENT ANALYSIS (R AND S)}

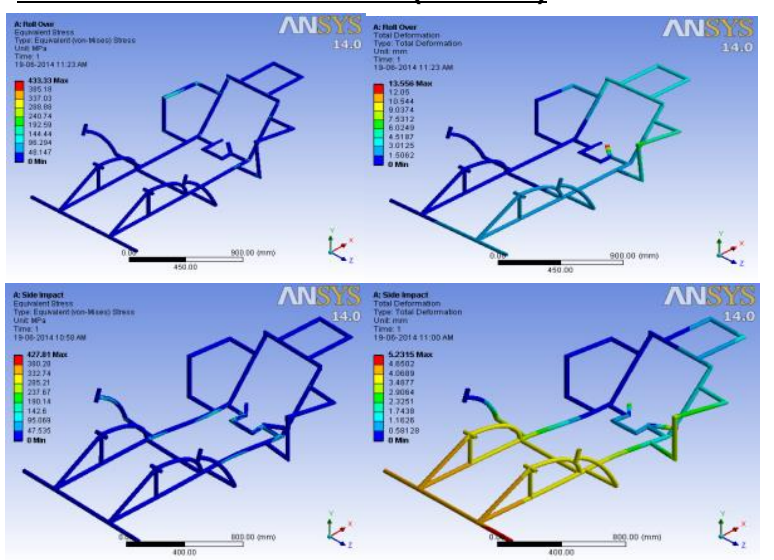

\section{FINITE ELEMENT ANALYSIS (F AND R)}

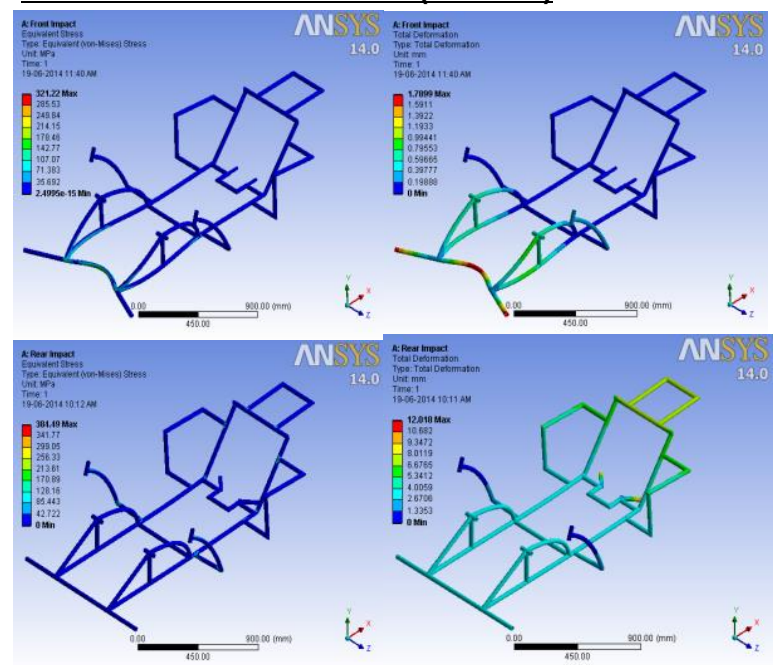

Fig 6: Finite Element Analysis of Chassis

\section{CONCLUSION}

The Efficycle was designed for the benefit of the humanity. It is an eco friendly human powered vehicle with a compounded electric drive system. The focus has been laid on the simplicity of design, high performance, easy maintenance and safety at very reasonable prices. The concept used in the innovation is programmable position control of gear shifter using stepper motors. Position of motors is controlled with respect to speed by programming which in turn controls the position of gear shifter. This technology is used in robotics \& position controlling of robotic arms. It has got a wide scope in automotive industry as it reduces the efforts of driver \& provides more automatic control of the vehicle. Hence it makes the vehicle more efficient. Human powered hybrid vehicle present the new milestone in the realm of "Green Technology".

\section{REFERENCES}

[1] SAE -NIS Efficycle 2012® rulebook.

[2] Gaffney, E. And Salinas, A." Introduction to Formula SAE® suspension and Frame Design“ ,SAE Technical Paper 971584, 1997, doi : 10.4271/971584.

[3] Sithananum C., Leelaphongprasut C., Baitiang C., Rnugpipatphol N., Noomwongs N., Singhanart T., "SAE Student Formula Space Frame Design and Fabrication", in The second TSME International Conference on Mechanical Engineering, Krabi, Thailand, 2011

[4] Product Data Sheet 304/304L Stainless steel, AK Steel

[5] F. Depenyou Jr, A.Doubla, S Laminsi, D.Moussa, J L Brisset, JM Le Breton, "Corrosion resistance of AISI 1018 carbon steel in $\mathrm{NaCl}$ solution by plasma-chemical formation of a barrier layer", in Corrosion Science, vol. 50, issue 5, May2008, pg:1422-1432.

[6] RN Jazar, "Vehicle Dynamics-Theory and Application", Chapter 7: Steering Dynamics, Springer, 2008 